\title{
PENGARUH KOMPOSISI MALAM TAWON PADA PEMBUATAN BATIK KLOWONG TERHADAP KUALITAS HASIL PEMBATIKAN
}

\author{
Abdul Malik ${ }^{1}$, Retno $^{2}$, Ayu $^{3}$ \\ Jurusan Teknik Kimia-Tekstil, Fakultas Teknologi Industri ,Universitas Islam Indonesia, ${ }^{1,2,3)}$ \\ Jl. Kaliurang Km.14, Sleman, Yogyakarta, 55584 \\ E-mail:malik_fti@yahoo.com
}

\begin{abstract}
Batik is a visual art that integral to the cultural identity as well as illustrates the life values upon which the life of community is laid. It uses a technique of wax resist dyeing applied to whole cloth. This research aims to know the composition of beeswax that required on batik klowong and to know its effect to the results. The research used both qualitative and quantitative methods such as ingredients measurement technique, questionnaire distribution and voters calculation. The wax for batik klowong consist of beeswax, resin, and white paraffin. The beeswax is an independent variable that is varied in the composition for five different sample (10 gram, 20gram, 30gram, 40gram, 50 gram). The sharpnesss of the motifs is visually analysed by six respondents. The results showed that sample $D$ and $E$ have better quality than the other samples. While sample A has the highest level of motifs sharpness.
\end{abstract}

Keywords : Composition, Beeswax, Batik Klowong, Quality.

\section{PENDAHULUAN}

Batik merupakan warisan budaya Indonesia yang tidak diragukan lagi keasliannya, terbukti dengan penghargaan batik sebagai salah satu warisan budaya dunia yang dihasilkan bangsa Indonesia oleh UNESCO pada tanggal 28 September 2009. Istilah Batik berasal dari kosa kata bahasa Jawa yaitu Amba dan Titik. Amba artinya kain dan titik adalah cara memberi motif pada kain dengan menggunakan malam cair dengan cara di titik - titik. Cara kerja membatik pada dasarnya adalah menutup permukaan kain dengan malam cair (wax) agar ketika kain dicelup kedalam cairan pewarna, kain yang tertutup malam tersebut tidak ikut kena warna. Jika proses membuat motif batik dilakukan dengan cara "ditulis" dengan menggunakan alat yang disebut canting, maka batik tersebut dinamakan batik tulis. Lilin batik adalah bahan yang digunakan untuk menutup permukaan kain menurut gambar motif batik, sehingga permukaan yang ditutup tersebut mempunyai sifat resist atau menolak warna yang diberikan pada kain. Pada awalnya bahan yang digunakan untuk menutup kain adalah bubur dari ketan, dan kain yang dibuat ini disebut kain simbut. Setelah diketemukannya lilin batik, bubur ketan sudah tidak dipakai lagi. Bahan pokok lilin adalah gondorukem, damar mata kucing, paraffin (putih dan kuning), Microwax, lemak binatang, minyak kelapa, lilin (malam) tawon, dan lilin lancing. Jumlah bahan pokok yang dipakai dan perbandingannya adalah bermacam macam, menurut pengalamannya masing masing. Jadi lilin batik itu sudah merupakan kombinasi dari bahan - bahan pokok lilin. Pada awalnya lilin batik hanya terbuat dari lilin tawon saja (orang jawa menyebutnya sebagai malam batik atau malam tawon), kemudian karena bertambah pengalamannya kemudian dicampur dengan gondorukem dan damar mata kucing. Kemudian untuk melemaskan atau menurunkan titik lelehnya maka dicampur dengan lemak binatang ataupun minyak kelapa (Susanto, 1975). Selama ini, masyarakat hanya mengetahui proses membatik dan lilin batik saja tanpa mengetahui pengaruh komposisi lilin batik itu sendiri terhadap hasil pembatikan. Untuk itu, penelitian ini dilakukan agar masyarakat lebih mengetahui pengaruh komposisi lilin batik tersebut dan lebih difokuskan pada 
pengaruh dari malam tawon yang merupakan salah satu bahan pokok lilin batik.

Tujuan Penelitian ini yaitu : untuk mengetahui komposisi malam tawon yang dibutuhkan pada lilin batik klowong dan apa pengaruh komposisi malam tawon terhadap kualitas hasil pembatikan.

\section{TINJAUAN PUSTAKA}

\subsection{Pengertian Batik}

Batik merupakan karya seni budaya tinggi bangsa Indonesia yang telah lama berkembang dan dikenal oleh masyarakat Indonesia (Susanto, 1975). Kata batik mempunyai beberapa pengertian. Menurut Hamzuri (2000), dalam bukunya yang berjudul Batik Klasik, pengertian batik merupakan suatu cara untuk memberi hiasan pada kain dengan cara menutupi bagianbagian tertentu dengan menggunakan perintang. Zat perintang yang sering digunakan ialah lilin atau malam. Kain yang sudah digambar dengan menggunakan malam kemudian diberi warna dengan cara pencelupan, setelah itu malam dihilangkan dengan cara merebus kain. Akhirnya dihasilkan sehelai kain yang disebut batik berupa beragam motif yang mempunyai sifat - sifat khusus.

\subsection{Lilin Batik}

Lilin batik adalah bahan yang dipakai untuk menutup permukaan kain menurut gambar motif batik, sehingga permukaan yang tertutup tersebut menolak atau resist terhadap warna yang diberikan pada kain tersebut. Lilin batik ini bukan merupakan terdiri dari satu macam bahan, tetapi campuran dari berbagai bahan pokok lilin. Sebagai bahan pokok lilin misalnya adalah gondorukem, damar (mata kucing), parafin (putih dan kuning), microwax, lemak binatang (kendal, gajih), minyak kelapa, lilin tawon, lilin lanceng.

\section{Lilin Batik Klowong}

Berfungsi untuk menutupi ragam hias dan desain batik yang dilakukan secara rengreng dan nerusi (bolak - balik di dua sisi permukaan kain). Kerangka motif yang menggunakan lilin ini biasanya merupakan isen-isen yang merupakan penghias dan ornament pada kain batik, misalnya seperti cecek, sawut, dan lain - lain.

\section{Lilin Tutupan atau Biron}

Berfungsi untuk menutupi warna motif tertentu yang dipertahankan pada kain pada kain setelah dicelup atau dicolet. Ciri cirinya yakni : mudah cair dan membeku, mudah dilorod, daya lekat cukup kuat, tidak tahan terhadap alkali.

\subsection{Bahan Pokok Lilin Batik}

Lilin dalam bidang pembatikan adalah suatu campuran padat dari beberapa bahanbahan pokok lilin. Bahan pokok lilin adalah bahan-bahan asli dari alam yang terdiri dari :

\section{Parafin}

Parafin adalah produk samping hasil pengolahan minyak bumi mentah, disebut juga lilin . Ada beberapa macam parafin yaitu parafin putih dan parafin kuning, keduanya berkristal seperti jarum, dan parafin 'getuk' yang tidak berkristal. Sifatsifat parafin antara lain :

- Mempunyai kelenturan dan daya rekat tinggi, titik leleh $52^{\circ} \mathrm{C}$ sampai $57^{\circ} \mathrm{C}$ mudah cair, mudah lepas dari kain, mudah patah, daya rekat kecil, lekas membeku, tidak tahan lama, tahan larutan alkali (caustic soda), tidak mudah menjadi karbon.

- Warna putih bersih dan kuning, parafin putih lebih bagus kualitasnya daripada parafin kuning. Parafin getuk berwarna putih, kurang baik kualitasnya untuk lilin batik.

Dalam perdagangan ada pula parafin cetak, baik berwarna putih atau kuning, kualitasnya lebih bagus daripada parafin getuk (di jual dalam wadah drum). Pemakaian parafin adalah untuk campuran lilin klowong dan lilin tembokan karena harganya murah. 


\section{Malam Tawon}

Nama lilin lebah dalam perdagangan adalah lilin tawon, lilin kote, lilin Palembang, lilin Sumbawa, lilin Timor. Disebut lilin kote, mungkin dahulu banyak dihasilkan dari daerah Kutai, Kalimantan utara. Lilin lebah merupakan bahan yang dikeluarkan oleh lebah melalui kelenjar di bawah perutnya. Lilin yang beku ini diletakkan pada sarangnya dengan bantuan kaki belakangnya.

Sifat - sifat malam tawon antara lain( BPKB, 1975) : titik leleh $58^{\circ} \mathrm{C}-60^{\circ} \mathrm{C}$, mudah cair, tahan lama, daya rekat tinggi, ulet, elastis, tidak berubah sifat - sifat fisisnya oleh perubahan suhu udara, pada panas tinggi tidak mudah mengkarbon, mempermudah lepasnya lilin waktu batik di lorod, menghaluskan tapak lilin, tidak berubah sifatnya dengan adanya perubahan hawa kemarau atau hujan. Warna kuning suram, ada yang warna kuning kecoklatan.

Lilin lebah dipakai sebagai bahan pokok lilin yang terbaik untuk pembuatan segala macam lilin, lebih - lebih digunakan untuk batik yang lama proses pengerjaannya. Lilin lebah baik digunakan untuk lilin pada batik yang akan dikerjakan dengan zat warna naftol, larutannya alkalis. Pilihlah lilin kote yang warnanya kuning suram, berlubang, berbau asam.

\section{Gondorukem}

Gondorukem dihasilkan oleh tanaman pinus (pinus mercusit juhn). Pohon ini bila disadap akan menghasilkan getah kental berwarna putih susu. Pada penyulingan getah pinus akan menghasilkan terpentin dan residunya merupakan masa padat berwarna kuning muda atau kuning kecoklatan bernama gondorukem.

Sifat titik leleh $+/-65^{\circ} \mathrm{C}$, lama cair, lama beku, daya rekat tinggi, tidak berubah sifat fisisnya oleh perubahan udara, mudah patah, pada panas tinggi tidak mudah mengkarbon, mempermudah lepasnya lilin waktu dilorod, tidak tahan terhadap larutan alkali, misal larutan kostik soda dan larutan soda abu.
Mutu gondorukem tergantung pada hasil penyulingannya. Apabila penyulingan yang dilakukan kurang seksama, terutama pada pengaturan suhu akan menghasilkan gondorukem bermutu rendah. Penyulingan uap akan menghasilkan gondorukem yang lebih baik, sedangkan penyulingan dengan suhu yang tinggi dan api langsung akan menyebabkan hasil gondorukem berwarna tua dan lengket (kurang rapuh).

\section{Damar Mata Kucing}

Damar dihasilkan dari getah pohon damar. Luka yang dibuat pada pokok pohon damar akan keluar getah. Getah yang tertumpuk pada permukaan luka dibagian kulit kayu, lama kelamaan akan membeku. Setelah tiga bulan getah yang mengeras ini menjadi damar yang berbentuk dan berukuran seperti telur ayam, dapat dipetik dan dikumpulkan, selanjutnya disortir berdasarkan warna, ukuran garis tengah butiran dan kebersihan.

\subsection{Malam Tawon atau "Kote"}

Malam tawon adalah lilin alami yang diproduksi dalam sarang lebah lebah madu dari genus Apis. Hal ini terutama ester asam lemak dan berbagai alkohol rantai panjang. Biasanya, untuk peternak lebah madu, 10 pon madu menghasilkan 1 pon lilin.Negara yang sudah menggunakan lilin lebah yaitu Amerika, Malaysia, Eropa dan Indonesia.

\section{Karakteristik Fisik Lilin Lebah}

Lilin lebah memiliki titik lebur tinggi dari $62^{\circ} \mathrm{C}-64^{\circ} \mathrm{C}\left(144^{\circ} \mathrm{F}-147^{\circ} \mathrm{F}\right)$. Jika lilin lebah dipanaskan di atas $85^{\circ} \mathrm{C}\left(185^{\circ} \mathrm{F}\right)$ akan terjadi perubahan warna. Titik nyala dari lilin lebah adalah $204,4^{\circ} \mathrm{C}\left(399,9^{\circ} \mathrm{F}\right)$. Densitas

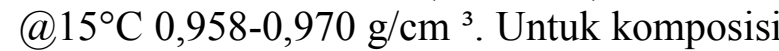
malam tawon dapat dilihat pada tabel .1 berikut ini. 
Tabel 1. Komposisi Malam Tawon

\begin{tabular}{lc}
\hline \multicolumn{1}{c}{ Wax Content Type } & Prosentase \\
\hline Hidroksi Polyester & $8 \%$ \\
Tidak Teridentifikasi & $6 \%$ \\
Hidroksi Monoesters & $4 \%$ \\
Monoesters & $35 \%$ \\
Triesters & $3 \%$ \\
Asam Polyester & $2 \%$ \\
Hidrokarbon & $14 \%$ \\
Diesters & $14 \%$ \\
Bebas Asam & $12 \%$ \\
Asam Ester & $1 \%$ \\
Bebas Alkohol & $1 \%$ \\
\hline
\end{tabular}

(Sumber : BPBK, 1975)

\section{METODE PENELITIAN}

Untuk mendapatkan data - data yang dibutuhkan maka digunakan metode metode sebagai berikut :

1. Uji laboratorium pembuatan lilin batik klowong yang meliputi uji komposisi dan uji hasil pembuatan.

2. Studi Pustaka dan Studi Lapangan Untuk memperoleh data-data yang mendukung, maka digunakan referensi buku literatur yang berhubungan dengan masalah yang dihadapi dan melakukan observasi ke Balai Penelitian Batik \& Kerajinan (BPBK) Yogyakarta.

\subsection{Alat dan Bahan Percobaan}

\subsubsection{Alat Percobaan}

Adapun alat - alat yang digunakan untuk percobaan yaitu :

- Membuat pola batik :

- Pensil.

- Kain mori yang biasa digunakan untuk membatik.

- Membuat sampel lilin percobaan :

- Wajan (untuk memanaskan lilin).

- Kompor.

- Alat pengaduk.

- Tempat / cetakan untuk menampung sampel lilin.
- Membuat batik :

- Canting klowong.

- Wajan.

- Kompor.

- Membuat pewarna batik :.

- Baskom (ember) untuk wadah pewarna.

- Wajan besar.

- Gelas beker.

\subsubsection{Bahan Percobaan}

Adapun bahan-bahan yang digunakan untuk percobaan ini yaitu :

- Resep sampel :

Sampel A :

- 20 gr damar mata kucing.

- 40 gr gondorukem.

- 10 gr parafin putih.

- 30 gr malam tawon.

Sampel B :

- 20 gr damar mata kucing.

- 40 gr gondorukem.

- 10 gr parafin putih.

- 10 gr malam tawon.

Sampel C :

- 20 gr damar mata kucing.

- 40 gr gondorukem.

- 10 gr parafin putih.

- 20 gr malam tawon.

Sampel D :

- 20 gr damar mata kucing.

- 40 gr gondorukem.

- 10 gr parafin putih.

- 40 gr malam tawon. 


\section{Sampel E :}

- 20 gr damar mata kucing.

- 40 gr gondorukem.

- 10 gr parafin putih.

- 50 gr malam tawon.

- Untuk membuat 5 (lima) resep sampel lilin tersebut maka dibutuhkan bahanbahan sebanyak :

- 100 gr damar mata kucing (@sampel=20 gr).

- 200 gr gondorukem (@sampel=40 gr).

- 50 gr parafin putih (@sampel=10 gr).

- 150 gr malam tawon (berbeda tiap sampel).
- Naphtol AS.OL dan Garam Scarlet GG untuk pewarnaan.

- Air dingin.

\subsection{Langkah Percobaan}

Langkah percobaan merupakan tahapantahapan yang dilakukan dari persiapan bahan baku hingga menjadi sesuatu yang dapat diamati sesuai dengan hasil yang diinginkan. Pada tiap proses terdapat tahapan - tahapan tersendiri. Untuk lebih jelas tentang langkah percobaan dari penelitian ini dapat dilihat pada gambar 1 berikut.

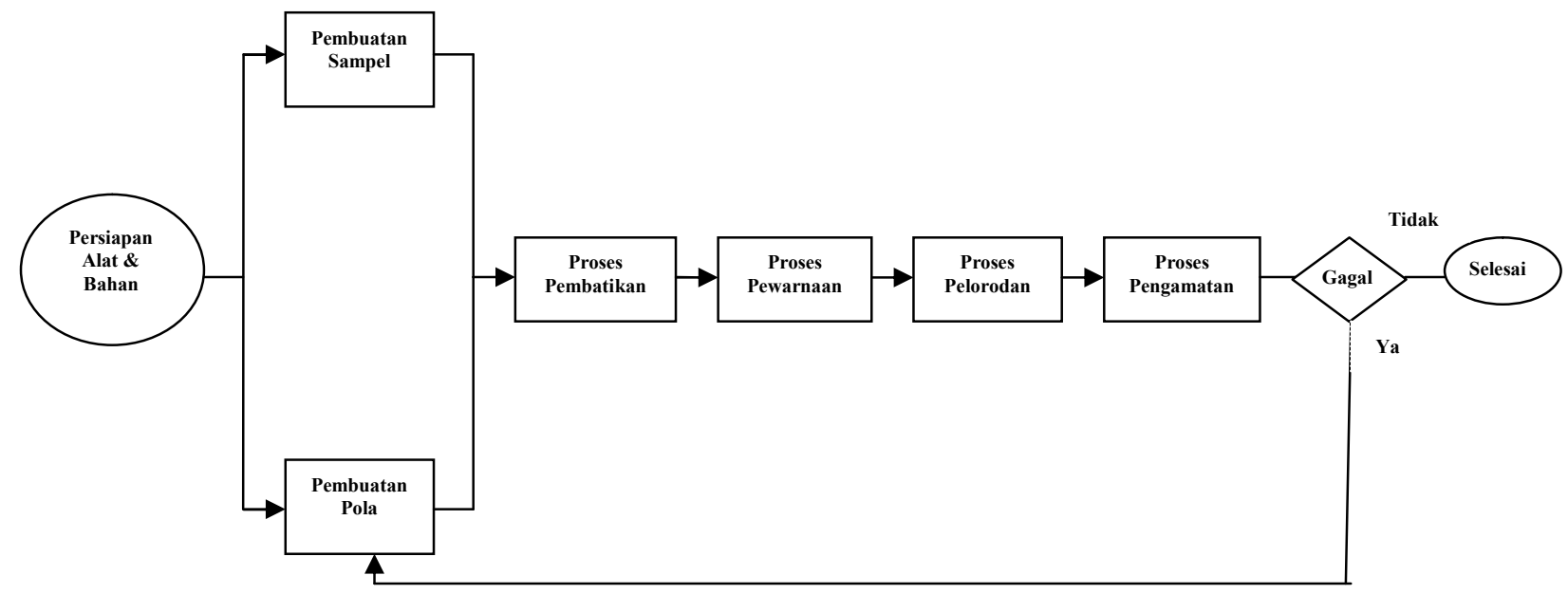

Gambar 1. Diagram Alur Proses Penelitian.

4. HASIL PENGUJIAN DAN PEMBAHASAN

\subsection{Uji Sampel Lilin}

Penelitian ini bertujuan untuk mendapatkan sampel dengan komposisi yang tepat untuk jenis batik klowong dengan pola garis dan titik. Parameter yang digunakan dalam penelitian ini yaitu komposisi malam tawon.

Untuk mendapatkan tujuan tersebut maka harus membuat beberapa komposisi sampel dengan kadar malam tawon yang berbeda - beda tiap sampelnya. Sampel yang dibuat pada penelitian ini sebanyak 5 (lima) sampel.
Bahan - bahan yang digunakan untuk membuat sebuah malam terdiri dari damar mata kucing, gondorukem, parain putih dan malam tawon. Setiap bahan mempunyai ciri - ciri dan fungsi masing - masing.

Damar mata kucing jika dilihat dari bentuknya seperti kaca agak kecoklatan dan bertekstur agak sedikit keras seperti gula batu. Jika dipanaskan, damar mata kucing akan cepat meleleh dan membentuk tekstur cairan yang kental berwarna kecoklatan. 


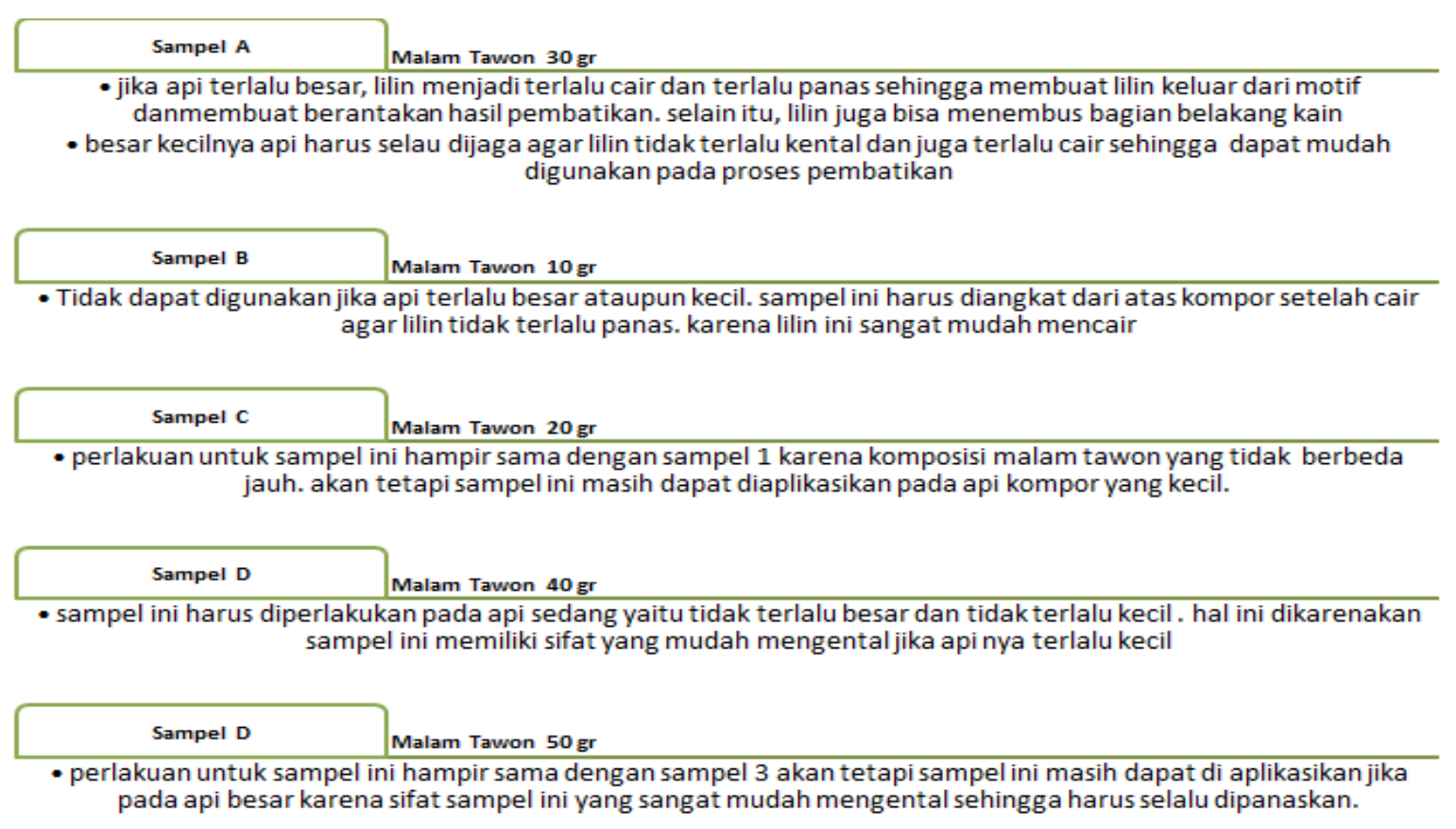

Gambar 2. Perlakuan Khusus Sampel Lilin.

Sedangkan gondorukem jika dilihat dari bentuknya seperti kaca bening berwarna kuning dan bertekstur sangat keras seperti kaca. Jika dipanaskan gondorukem sama seperti damar mata kucing yang akan membentuk cairan agak sedikit kental berwarna kuning.

Selanjutnya parafin putih yang jika dilihat dari bentuknya seperti lilin biasa berwarna putih dan bertekstur agak sedikit lembut. Jika dipanaskan akan menjadi sedikit cair dan jernih seperti minyak. Yang terakhir yaitu malam tawon yang jika dilihat dari bentuknya seperti getah pohon yang bertekstur sangat lembut dan lengket berwarna coklat hampir ke kuning kuningan. Jika dipanaskan malam tawon akan membentuk cairan yang sedikit kental berwarna coklat. Malam tawon sedikit susah untuk dicairkan karena teksturnya yang lembut dan lengket.

Setiap sampel lilin mempunyai perlakuan khusus pada saat proses pembatikan agar hasilnya sesuai dengan yang diharapkan. Berdasarkan hasil pengamatan, perlakuan khusus yang harus dilakukan pada sampel lilin dapat dilihat pada gambar 2 diatas.
Perlakuan pada setiap sampel harus disesuaikan dengan sifat dari masing masing bahan. Untuk memperoleh hasil pembatikan yang bagus, perlakuan khusus harus dilakukan agar kualitas sampel lilin tetap baik dan tidak mudah rusak. Jika sampel lilin diperlakukan dengan salah, maka sampel lilin dapat menjadi tidak bagus lagi sehingga akan berpengaruh terhadap hasil pembatikan.

Salah satu ciri dari sampel lilin yang tidak bagus lagi dapat dilihat dari warnanya yang berbeda dari pertama pemakaian yaitu berwarna coklat kehitaman. Sampel lilin yang terus dipanaskan menggunakan api yang besar dapat menyebabkan perubahan warna tersebut. Sampel lilin yang tidak bagus lagi tetap dapat digunakan akan tetapi akan terlihat perbedaannya pada proses pembatikan.

Dari pengujian sampel lilin dapat disimpulkan bahwa sampel lilin E merupakan sampel lilin yang paling baik diantara yang lainnya. Hal ini dikarenakan sampel lilin tersebut mempunyai komposisi 
Tabel 2. Penilaian Tingkat Ketajaman Motif Hasil Pembatikan

Tingkat Ketajaman Motif

No. Sampel

Sangat Baik Baik Cukup Baik Jelek Sangat Jelek

\begin{tabular}{lccccc}
\hline Sampel A & 6 & 1 & 2 & 0 & 0 \\
Sampel B & 1 & 7 & 1 & 0 & 0 \\
Sampel C & 0 & 4 & 3 & 2 & 0 \\
Sampel D & 0 & 6 & 2 & 1 & 0 \\
Sampel E & 1 & 3 & 5 & 0 & 0 \\
\hline
\end{tabular}

malam tawon yang paling banyak diantara sampel yang lainnya.

Selain itu, pada saat pengamatan sampel lilin E merupakan sampel yang mempunyai daya lentur yang paling baik dan tidak mudah patah. Jika dilihat dari proses pembatikan, sampel lilin E merupakan sampel yang paling mudah untuk digunakan. Sampel lilin E tersebut dapat dilepaskan dengan mudah dari kain pada saat lilin telah kering dan tidak meninggalkan bekas pada kain.

Sampel A, B, C, D terbilang masih kurang cukup baik jika dilihat pada pengujian sampel lilin. Hal ini dikarenakan sampel - sampel tersebut memiliki komposisi malam tawon yang lebih rendah dibandingkan dengan komposisi gondorukemnya. Jika komposisi gondorukem terlalu besar pada suatu sampel, maka akan menyebabkan sampel lilin tersebut menjadi rapuh dan mudah patah jika tidak hati - hati.

Selain itu, sampel lilin akan menjadi cepat cair dan cepat membeku sehingga akan sulit digunakan pada proses pembatikan.

\subsection{Uji Ketajaman Motif}

Pengujian ketajaman motif ini dilakukan dengan menggunakan metode angket (kuisioner) dengan penilaian secara kualitatif dan kuantitatif. Penilaian secara kualitatif dilakukan dengan memberikan pendapat ataupun tanggapan dari sampel secara visual sedangkan penilaian secara kuantitatif dilakukan dengan menghitung banyaknya jumlah responden yang memilih dan memberi nilai baik pada sampel.

Jumlah responden pada pengujian ini adalah sebanyak 6 orang. Setiap responden diminta untuk memberi nilai pada masing masing sampel dengan melihat pada ketajaman motif sampel. Hasil dari penilaian angket (kuisioner) dapat dilihat pada tabel .2 diatas.

Jika dibuat dalam bentuk grafik, akan sangat jelas terlihat hasil pengamatan tingkat ketajaman motif dari sampel - sampel tersebut. Untuk lebih jelasnya dapat dilihat pada gambar 3 berikut ini. 


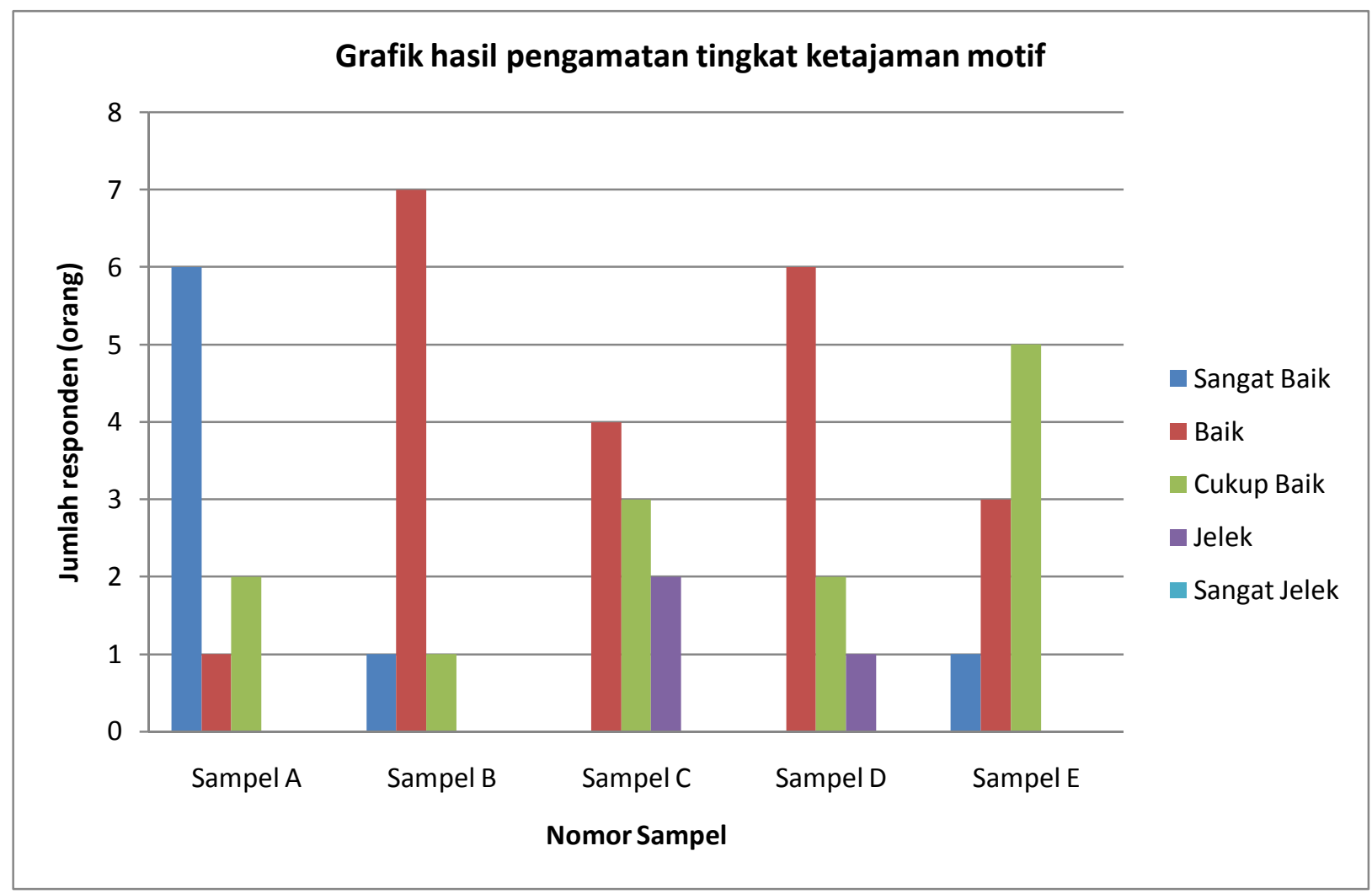

Gambar 3. Grafik Hasil Pengamatan Tingkat Ketajaman Motif.

Berdasarkan hasil grafik tesebut, maka dapat dijelaskan sebagai berikut :

- Pada sampel A, hampir seluruh jumlah responden memberi nilai 1 yaitu sangat baik sehingga dapat disimpulkan sampel A merupakan sampel yang memiliki tingkat ketajaman motif paling baik.

- Pada sampel B, dari 9 responden yang memberi nilai sangat baik sebanyak 1 orang, nilai baik sebanyak 7 orang dan nilai cukup baik sebanyak 1 orang. Sehingga dapat disimpulkan jika sampel B memiliki tingkat ketajaman motif baik.

- Pada sampel C, dari 9 responden yang memberi nilai baik sebanyak 4 orang, nilai cukup baik sebanyak 3 orang dan nilai jelek sebanyak 2 orang. Sehingga dapat disimpulkan jika sampel C memiliki tingkat ketajaman motif baik.
- Pada sampel D, dari 9 responden yang memberi nilai baik sebanyak 6 orang, nilai cukup baik sebanyak 2 orang dan nilai jelek sebanyak 1 orang. Sehingga dapat disimpulkan jika sampel D memiliki tingkat ketajaman motif baik.

- Pada sampel E, dari 9 orang responden yang memberi nilai sangat baik sebanyak 1 orang, nilai baik sebanyak 3 orang dan nilai cukup baik sebanyak 5 orang. Sehingga dapat disimpulkan jika sampel E memiliki tingkat ketajaman motif cukup baik.

Berdasarkan penjelasan tersebut, disimpulkan bahwa sampel A memiliki kualitas tingkat ketajaman motif paling baik dibandingkan dengan sampel lainnya. Hal ini dapat dilihat dari hasil angket (kuisioner) yang telah dilakukan. Hampir seluruh responden memberikan nilai sangat baik untuk sampel 1. 


\section{KESIMPULAN}

Dari penelitian dan kajian yang dilakukan maka dapat disimpulkan bahwa :

1. Semakin banyak jumlah malam tawon, maka semakin lentur lilin yang akan dihasilkan dan lilin tersebut menjadi tidak mudah patah.

2. Sampel lilin E merupakan sampel lilin yang paling baik diantara sampel yang lainnya.

3. Sampel A merupakan sampel yang paling baik dilihat dari tingkat ketajaman motif.

\section{DAFTAR PUSTAKA}

Balai Penelitian Batik dan Kerajinan, Penelitian Lilin Lebah (malam tawon), Departemen perindustrian, BPBK, Yogyakarta, 1975.

Hamzuri, Batik Klasik, Penerbit Jambatan, Jakarta, 2000.

Susanto, SK, Seni Kerajinan Batik Indonesia, BBKB, Yogyakarta, 1975. 